\title{
Effect of Nickel on Emission Intensities of Volatile Elements with High Excitation Potential in Direct-Current Arc
}

\author{
A. Rehber TÚrker*, Süleyman AKmaN* and Latif Elçi** \\ *Gazi Üniversitesi, Fen-Edebiyat Fakültesi, Ankara, Turkey \\ **Erciyes Üniversitesi, Fen-Edebiyat Fakültesi, Kayseri, Turkey
}

\begin{abstract}
In this study the effect of nickel as a modifier on the spectral line intensities of $\mathrm{As}$, $\mathrm{Sb}$ and $\mathrm{Hg}$ in d.c. arc was investigated. As a result of nickel addition into the sample, spectral line intensities of the elements decreased at low current strengths and increased at higher current strengths. It was concluded that the effect of nickel on $\mathrm{As}, \mathrm{Sb}$ and $\mathrm{Hg}$ is due to the formation of thermally stable compound between nickel and the element to be determined.
\end{abstract}

Keywords Direct-current arc emission spectroscopy, arsenic, antimony, mercury, matrix modification, nickel oxide

A number of interesting studies on the reactions in arc plasma and electrodes have been investigated by now. ${ }^{1-3}$ It is known that various substances empirically selected are being added to the sample in order to establish better evaporation conditions. The effects of these additives on the arc processes are different.

The complete excitation process consists of a complex chemical and physical phenomena in the electrode and plasma which influence each other. These effects are the thermochemical reactions of sample components in the electrode, transport of sample material from the electrode, evaporation, chemical reactions and transport phenomena in the plasma and the excitation of atoms and ions to higher energy levels. As a result of these processes the intensity of spectral lines changes from element to element and from matrix to matrix for a particular element. For many years, numerous authors have been investigating the influence of thermochemical reactions on spectroscopic results, which have yielded valuable knowledge concerning mechanisms of various process in this field. ${ }^{4-6}$

To improve the detection limits in spectrochemical analysis using the d.c. arc, one often uses additives. But for easily-volatile elements having high excitation potential there are no special additives which have been used up to now. Only Waring et al. ${ }^{7}$ reported that the addition of $\mathrm{CuO}$ to the sample enhanced the intensity of selenium spectral lines. But the reason of this effect was not discussed. These elements volatilize from the arc so rapidly that it becomes extremely difficult for the optical system to detect and record their emission spectra. In addition, because of the absence of proper operating conditions and equipment for the slow and uniform volatilization of these ele- ments in direct-current arc, determination of them is not easy. The low sensitivity of these elements results partly from absorption of the light energy by any quartz in the optical system and partly from absorption of the low wavelength light by oxygen in the air and gelatin in the photographic emulsion. High excitation potentials of these elements, which are usually above the ionization potential of the elements forming the matrix of the sample are another difficulty to be overcome. ${ }^{8}$

In the graphite furnace AAS analysis, when ashing temperatures high enough to remove the matrix are applied, some analyte may volatilize before atomization. On the other hand, when low ashing temperatures are applied to prevent the analyte losses, then the matrix remains in the furnace and volatilizes during the atomization step with analyte. Interaction between analyte and matrix species in condensed phase or gas phase mostly affects the result of analysis. For this reason mentioned above, matrix modification proposed by Ediger ${ }^{9}$ almost a decade ago is a very important improvement in GFAAS analysis because it allows considerably higher thermal pretreatment temperatures to be used and makes the behaviour of the element to be determined in the graphite furnace much more predictable. In addition, this was and is the main purpose of matrix modification, it facilitates significantly the volatilization and separation of matrix constituents prior to the atomization of the analyte element. In the analysis of $\mathrm{As}, \mathrm{Sb}, \mathrm{Se}$ and $\mathrm{Te}$ in GFAAS, matrix modification by addition of several metals such as $\mathrm{Pd}, \mathrm{Pt}, \mathrm{Ni}, \mathrm{Ag}$ or $\mathrm{Cu}$ to the sample solutions reduces the analyte volatilization loss during ashing step by formation of thermally-stable compounds between modifier and analyte element. ${ }^{10-13}$ 
Nowadays in the analysis of $\mathrm{As}, \mathrm{Sb}, \mathrm{Se}$ and $\mathrm{Te}$ nickel is widely applied for this purpose. It is believed that, a compound formed between $\mathrm{As}$ ( $\mathrm{Sb}, \mathrm{Se}$ or $\mathrm{Te}$ ) and $\mathrm{Ni}$ atomizes suddenly at higher temperatures than those without modifier. As a result, higher ashing temperatures can be applied and equally important less gas-phase combination between matrix species and analyte element occurs because atomization takes place at higher temperatures.

There is no reason for the same effect not to happen in graphite electrodes and plasma of d.c. arc. If this is true, nickel can be used as an additive (modifier) in the determination of metalloids such as $\mathrm{As}, \mathrm{Sb}, \mathrm{Se}$ and $\mathrm{Te}$ in d.c. arc. It may be expected that, when the metalloid sample is mixed with $\mathrm{Ni}$ (as an oxide or nitrate form), the same less volatile compound as in AAS would form, which vaporizes and atomizes at higher electrode and plasma temperatures, respectively. This causes a more efficient excitation of metalloid atoms in arc plasma because when the atoms begin to be excited, the plasma temperature is higher than that without nickel. The more efficient excitation, the more intense spectral lines are. On the other hand, if nickel-metalloid compound can not decompose in arc-plasma efficiently during its residence time, less intense spectral lines will result.

The aim of this paper is to investigate applicability of modifiers which are widely used in GFAAS analysis, to the d.c. arc analysis. The influence of $\mathrm{NiO}$ on spectral line intensity of easily-volatile elements such as $\mathrm{As}, \mathrm{Sb}$ and $\mathrm{Hg}$ was investigated. Results were compared with data obtained with graphite as the additive. A change was observed in spectral line intensities and signal-to-background ratios.

\section{Experimental}

\section{Apparatus and experimental conditions}

Spectrograph: $3.4 \mathrm{~m}$ Ebert type Jarrell-Ash spectrograph; slit width: $30 \mu \mathrm{m}$.

Excitation: Jarrell-Ash d.c. arc. Current strenght: 5,8,12 A.

Electrodes: graphite electrodes from RingsdorfWerke, RW 103, RW 0076 and RW 0067. The lower electrode (anode) had a sample cavity $4.5 \times 4.5 \mathrm{~mm}$, while the upper electrode had a conically rounded end. The analytical gap adjusted manually to positions on outside target was $4 \mathrm{~mm}$.

Emulsion: AGFA-GEVAERT 34 B 50 plates.

Microphotometer: Jarrell-Ash microphotometer with $7 \mu \mathrm{m}$ slit width and $0.5 \mathrm{~mm}$ slit height. A computer program was used for conversion of densitometric readings to relative intensities using the Kaiser transform.

Spectral lines: Sb $287.79 \mathrm{~nm}$, As $286.05 \mathrm{~nm}$ and $\mathrm{Hg}$ $253.65 \mathrm{~nm}$.

The lines of the elements which were free from interferences were used.
Exposure: 40 s. Pre-exposure: 5 s. Spectrum: first order.

\section{Sample preparation}

The standard used in this study is synthetic standard which contains $\mathrm{As}, \mathrm{Sb}$ and $\mathbf{H g}$ in ultrapure graphite powder matrix.

Elements were mixed with graphite in their oxide forms. $\mathrm{NiO}$ used as an additive was mixed with synthetic standard. Small quantities of $\mathrm{ZnO}$ were added for the investigation of plasma temperatures. The final concentration of the elements and $\mathrm{NiO}$ were $1 \%$ and $40 \%$, respectively based on total amount of mixture. The mixture subsequently is packed in a graphite cup electrode and arced in d.c. discharge.

\section{Measurement of arc temperature}

The temperature was measured from the intensity ratio of zinc line pairs, $\mathrm{Zn} 307.6 \mathrm{~nm}$ and $\mathrm{Zn} 307.2 \mathrm{~nm}$. The application of this method, most frequently used in the spectrochemical literature, is based on the assumption of local thermal equilibrium (LTE) in the plasma. $^{14}$

\section{Results and Discussion}

\section{Dependence of enhancement effect on concentration of additive}

The influence of the concentration of the added $\mathrm{NiO}$ on spectral line intensities of all the investigated elements was observed. The results obtained for the elements are shown in Fig. 1. By comparing the relative line intensities of the elements with and without additive, it is possible to determine optimum concentration of additive $(40 \% \mathrm{NiO})$. The influence of $\mathrm{NiO}$ is enhanced by increasing its concentration and for a

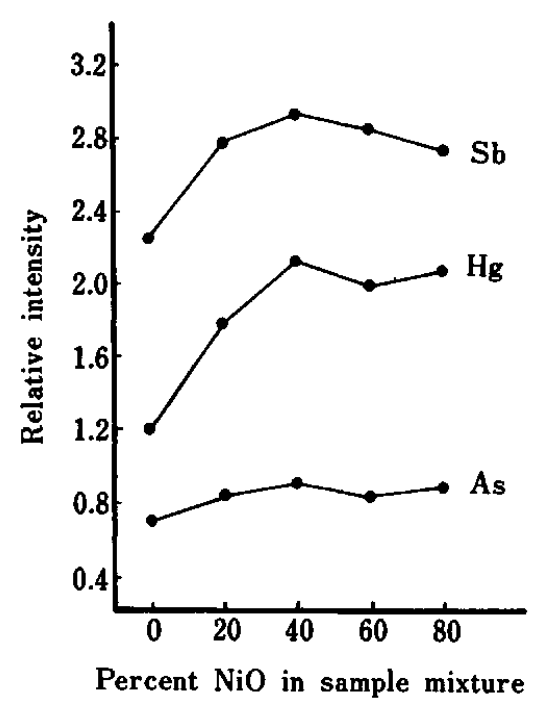

Fig. 1 Relative intensity as a function of nickel oxide concentration in the sample mixture. 
Table 1 Dependence of enhancement factors of line intensities $(I)$ and signal-to-background ratios (SBR) on the current strength

\begin{tabular}{|c|c|c|c|c|c|c|}
\hline \multirow{3}{*}{ Element (nm) } & \multicolumn{6}{|c|}{ Current strength/A } \\
\hline & \multicolumn{2}{|c|}{5} & \multicolumn{2}{|c|}{8} & \multicolumn{2}{|c|}{12} \\
\hline & $f$ & $\boldsymbol{F}$ & $f$ & $\boldsymbol{F}$ & $f$ & $\boldsymbol{F}$ \\
\hline $\begin{array}{l}\mathrm{As}(286.05) \\
\mathrm{Sb}(287.79) \\
\mathrm{Hg}(253.65)\end{array}$ & $\begin{array}{l}0.87 \\
0.41 \\
1.42\end{array}$ & $\begin{array}{l}0.75 \\
0.62 \\
1.44\end{array}$ & $\begin{array}{l}1.44 \\
0.66 \\
1.83\end{array}$ & $\begin{array}{l}1.85 \\
0.64 \\
1.86\end{array}$ & $\begin{array}{r}11.23 \\
1.24 \\
31.07\end{array}$ & $\begin{array}{r}3.85 \\
0.90 \\
27.11\end{array}$ \\
\hline
\end{tabular}

Values are mean of five replicates. $f=I_{\mathrm{N}} / I_{\mathrm{G}}$ and $F=$ $(\mathrm{SBR})_{\mathbf{N}} /(\mathrm{SBR})_{\mathbf{G}}$, where subscript $\mathbf{N}$ denotes $\mathrm{NiO}$ additive and $G$ refers to graphite.

majority of the compound there is a saturation effect for concentrations greater than $40 \%$.

\section{Influence of $\mathrm{NiO}$ on arc temperature}

When discussing the observed enhancement effect, it is necessary to consider whether the plasma parameters change. For this reason the arc temperature was measured. The arc temperatures are $6610 \pm 155$ $\mathrm{K}$ and $6630 \pm 106 \mathrm{~K}$ with the addition of $\mathrm{NiO}$ and graphite, respectively with 10 A current strength. The results are an average of seven replicates. A survey of the results shows that $\mathrm{NiO}$ has not an appreciable influence on the temperature.

\section{Enhancement factors and the effect of current strength}

The ratio of spectral line intensities with and without $\mathrm{NiO}$ was determined. The addition of $40 \% \mathrm{NiO}$ causes a greater enhancement effect in line intensities and in signal-to-background ratios at higher current strengths (Table 1). The dependence of spectral line intensities on current strength is shown in Figs. 2 and 3 with the addition of $\mathrm{NiO}$ and graphite powder, respectively. As can be seen from the figures and Table 1 , the addition of nickel decreases the line intensities at low current strengths and increases at high current strengths compared to addition of graphite. The enhancement factors show increasing trend with increasing current strength.

In AAS studies, it is accepted that, nickel, which is used as a modifier, forms a hardly volatile but easilydecomposing compound with $\mathrm{Sb}$ and As. The compound between nickel and As (or Sb), which is assumed to be $\mathrm{Ni}\left(\mathrm{AsO}_{3}\right)_{2} \mathrm{NiO}$ (or $\mathrm{Ni}\left(\mathrm{SbO}_{3}\right)_{2} \mathrm{NiO}$ ) is formed at about $400^{\circ} \mathrm{C}$ during ashing step in condense phase. ${ }^{15,16}$ The formation of these compounds increase the initial loss temperature for As from 300 to $1300^{\circ} \mathrm{C}$ and for $\mathrm{Sb}$ from 700 to $1000^{\circ} \mathrm{C}$. On the other hand, peak areas with and without nickel are the same. That means these compounds hardly vaporize but at the atomization step temperatures of $2000-2500^{\circ} \mathrm{C}$ atomize as easy as the standard As (or Sb) samples do. In addition, a gas phase interference between nickel and As (or $\mathrm{Sb}$ ) seems not to be possible.

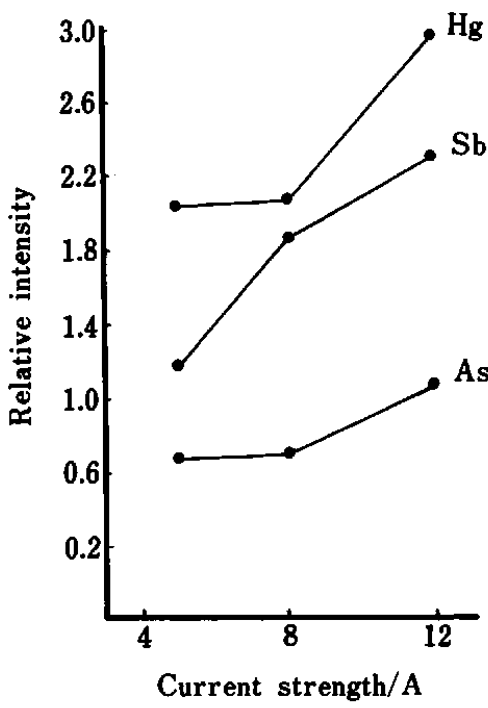

Fig. 2 The dependence of spectral line intensity of the investigated elements on the current strength in the presence of nickel oxide.

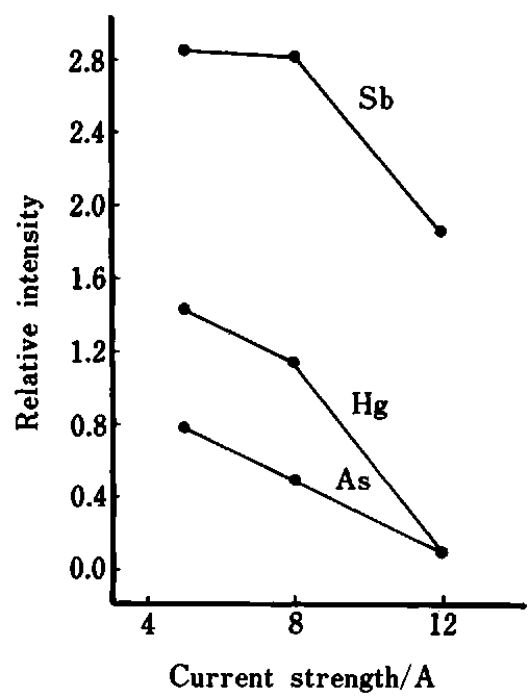

Fig. 3 The dependence of spectral line intensity of the investigated elements on the current strength in the presence of graphite powder.

$A$ reaction between nickel and $A s$ (or $S b$ ) in the gas-phase such as

$$
\mathrm{Ni}(\mathrm{g})+\mathrm{As}(\mathrm{g}) \rightleftharpoons \mathrm{NiAs}(\mathrm{g})
$$

is to the favour of left side during atomization step.

By considering all these facts which are valid in graphite-furnace AAS, the same events can be expected in d.c. arc. In the cavity of the electrode before the volatilization of analyte element, the formation of the same compound as in graphite furnace $\left(\mathrm{NiO}\left(\mathrm{AsO}_{3}\right)_{2} \mathrm{NiO}\right.$ or $\left.\mathrm{NiO}\left(\mathrm{SbO}_{3}\right)_{2} \mathrm{NiO}\right)$ can be assumed. 
The conditions for the formation of the same compound in the electrode, whose temperature is at least $1000^{\circ} \mathrm{C}$, is fulfilled. In AAS, the compound between $\mathrm{Ni}$ and $\mathrm{As}$ (or $\mathrm{Sb}$ ) is formed at about $400^{\circ} \mathrm{C}$ during ashing step. At low current strengths, which means low electrode and plasma temperatures ${ }^{17}$, the compound between nickel and the analyte element can not decompose to its elements efficiently as much as the standard analyte sample can during the very short residence time because of the relatively low plasma temperatures. As a result, at low current strengths, the line intensities of analyte element with the addition of nickel is lower than those without nickel. On the other hand, when current strength increases, electrode and plasma temperature will increase more rapidly and thermally stable compound will be transported to higher temperature medium. As a result, the compound between $\mathrm{NiO}$ (modifier) and analyte element decomposes more efficiently at higher temperatures during the residence time and more intense lines will result. More intense lines with nickel at higher current strengths can be understood by this fact. Similar results have been obtained in AAS studies. At very low atomization temperatures, peak area with modifier is less than that without modifier because of the incomplete atomization of thermallystable compound.

\section{References}

1. R. Boniforti, A. Clancia and G. Di Giorgio, Spectrochim. Acta, 27B, 309 (1972).
2. N. Krasnobaeva and Z. Zadgorska, Spectrochim. Acta, 29B, 191 (1974).

3. A. R. Türker and M. Doğan, Spectrochim. Acta, 41B, 959 (1986).

4. V. Vukanovic, N. Ikonomov and B. Pavlovic, Spectrochim. Acta, 26B, 95 (1971).

5. B. Pavlovic, V. Vukanovic and N. Ikonomov, Spectrochim. Acta, 26B, 109 (1971).

6. A. Delijska, Chr. Pravceva and C. Toncev, Spectrochim. Acta, 31B, 121 (1976).

7. C. L. Waring, H. Worthing and K. V. Hazel, Anal. Chem., 30, 1504 (1958).

8. G. R. Harrison, R. C. Lord and J. R. Loofbourow, "Practical Spectroscopy", Prentice-Hall, New York (1948).

9. R. D. Ediger, At. Absorption Newslett., 14, 127 (1975).

10. W. Slavin, G. R. Carnrick and D. C. Manning, Anal. Chem., 54, 621 (1982).

11. G. F. Kirkbright, Hsiao-Chuan and R. D. Snook, At. Spectrosc., 1, 85 (1980).

12. E. J. Hinderberger, M. L. Kaiser and S. R. Koirtyohann, At. Spectrosc., 2, 1 (1981).

13. M. L. Kaiser, S. R. Koirtyohann, E.-J. Hinderberger and H. E. Taylor, Spectrochim. Acta, 36B, 773 (1981).

14. P. W. J.' M. Boumans, "Theory of Spectrochemical Excitation", Hilger and Watts, London (1966).

15. J. Koreckova, W. Frech, E. Lundberg, J. A. Persson and A. Cedergren, Anal. Chim. Acta, 130, 267 (1981).

16. B. Welz, S. Akman and G. Schlemmer, Analyst [London], 110, 459 (1985).

17. R. J. Decker and D. J. Eve, Applied Spectrosc., 23, 31 (1969).

(Received November 17, 1986)

(Accepted December 6, 1986) 